\title{
NILAI-NILAI NASIONALISME PERJUANGAN HASSAN BASRY SEBAGAI SUMBER BELAJAR SEJARAH
}

\author{
Syaharuddin, Heru Puji Winarso, Al Hidayatullah \\ Prodi. Pendidikan Sejarah, FKIP, Universitas Lambung Mangkurat \\ Syahar@ulm.ac.id
}

Abstract: $\quad$ Indonesia is experiencing nationalism degradation with high degree of corruption from top to lowest level of government; uncontrolled natural resources exploitation; and high level of intolerance. On the other hand, history teacher inability to explore local sources as a learning media, as Hasan Basry roles in Indonesia revolution of independence in South Kalimantan, have resulted in student low understanding towards their local identity and history. Hasan Basry was a patriot in revolution of independence (1945-1949) in Lambung Mangkurat land. The proclamation of 17th May in Kandangan was Hasan Basry contribution filling with nationalism spirit that important in student character building through historical studies. It is highly transformative as a source of learning as well as inspiring public of nationalism in local context. Nationalism values of Hasan Basry also resembles in the post-war period with his initiative in the formation of Lambung Mangkurat University and his roles as its first president (rector) in 1958.

Abstrak: $\quad$ Nasionalisme Indonesia saat ini sedang mengalami degradasi yang diantaranya ditandai dengan semakin tingginya angka korupsi baik di kalangan pejabat pusat maupun daerah; eksploitasi terhadap alam (SDA) secara massif yang berdampak terhadap kehidupan masyarakat; dan semakin tingginya sikap intoleransi yang mengarah kepada disintegrasi bangsa. Di sisi lain, kurang optimalnya kemampuan guru sejarah dalam memanfaatkan sumber-sumber lokal, seperti peran Hassan Basry dalam mempertahankan kemerdekaan di Kalimantan Selatan yang berimplikasi terhadap rendahnya pengetahuan dan pemahaman peserta didik terhadap sejarah lokalnya. Hassan Basry adalah tokoh pejuang pada periode revolusi fisik (1945-1949) yang memiliki peran penting dalam mempertahankan kemerdekaan di bumi Lambung Mangkurat. Pernyataan "Proklamasi 17 Mei" di Kandangan oleh Hassan Basry, mengandung nilai nasionalisme yang memiliki fungsi strategi terhadap pembentukan karakter bagi peserta didik melalui pembelajaran sejarah. Pernyataan tersebut mengandung nilai-nilai nasionalisme yang sangat penting diinternalisasikan dan ditransformasikan kepada peserta didik sebagai sumber belajar sejarah. Nilai nasionalisme Hassan Basry tidak berhenti pada periode revolusi fisik, tapi berlanjut hingga pascarevolusi fisik, yakni menggagas dan menjadi presiden (rektor) pertama Universitas Lambung Mangkurat (ULM) (1958).

Kata Kunci: $\quad$ nilai nasionalisme, Hasan Basry, sumber belajar, pembelajaran sejarah

\section{PENDAHULUAN}

Nasionalisme Indonesia merupakan suatu fase yang baru mulai disebut dengan jelas dan terorganisir pada dasarwarsa abad ke 20, namun kebanyakan unsur pokoknya yang penting sudah ada jauh sebelumnya (Kahin, 1995). Pada awal abad 20 juga sudah muncul kesadaran identitas bersama, yang ditandai dengan didirikannya berbagai organisasi oleh para elite, baik yang bersifat politik, kultural maupun agama, seperti Sarekat Islam (1911), Indische Partij (1912), Budi Utomo (1980), Taman Siswa, Muhammadiyah dan Nahdatul Ulama. Para elite itu kemudian membangun kesadaran nasionalisme melalui pendidikan, baik pendidikan umum maupun pendidikan Islam (Syaharuddin, 2017). Kesadaran yang telah dibangun oleh para elite itu berlanjut hingga pascakemerdekaan (19451949), termasuk di Kalimantan Selatan dimana Hassan Basry merupakan tokoh utama dalam perjuangan tersebut.

Nasionalisme menurut Kahin merupakan suatu paham yang menciptakan dan mempertahankan kedaulatan sebuah negara dengan mewujudkan satu konsep identitas bersama untuk sekelompok manusia bangsa (Anwar, 2014). Nasionalisme merupakan konsep yang diyakini berfungsi untuk menjaga keutuhan. Nasionalisme masa kini adalah suatu kesadaran sebagai bangsa yang disertai oleh hasrat untuk memelihara, melestarikan dan mengajukan identitas, integritas, memiliki ketangguhan karakter bangsa yang kuat dan beradab (Anwar, 2014). Sejalan dengan Kemendiknas (2010) menjelaskan bahwa nilai cinta tanah air (patriotisme) adalah cara berfikir, bersikap, dan berbuat yang menunjukkan kesetiaan, kepedulian, dan penghargaan yang tinggi terhadap bahasa, lingkungan fisik, sosial, budaya, ekonomi, dan politik bangsa. Hassan Basry sebagai tokoh pejuang dari Kalimantan Selatan periode revolusi fisik (1945-1949) memiliki fungsi strategi dalam membentuk karakter cinta Tanah Air (Patriotisme).

Patriotisme dalam konteks pendidikan sebagaimana dijelaskan dalam Kemendiknas, maka menurut Anwar (2014) nilai-nilai patriotisme harus menjadi pembiasaan di sekolah seperti melalui kegiatan rutin, kegiatan spontan, kegiatan pemberian keteladanan, maupun kegiatan terprogram. Bining dan Bining (Wiriaatmadja, 2002) menjelaskan tujuan pengajaran sejarah, yaitu untuk memberikan pendidikan moral dan menanamkan kesadaran nasionalisme dan patriotism, serta menjadi warga negara yang baik. Hassan Basry adalah sosok pahlawan nasional yang memiliki nilai- 


\section{Syaharuddin, Heru Puji Winarso, Al Hidayatullah \\ Nilai-Nilai Nasionalisme Perjuangan Hassan Basry sebagai Sumber Belajar Sejarah}

nilai nasionalisme dan patriotism tinggi yang tampak selama masa perjuangannya dalam mempertahankan Kalimantan Selatan dari Belanda/NICA. Hal ini memiliki fungsi strategis terhadap pembentukan karakter bangsa (nation and character building), yakni terbentuknya sikap cinta Tanah Air.

Diantara aspek untuk membangun kesadaran sejarah, yaitu pengetahuan tentang fakta-fakta sejarah, yang mewujudkan bangsa Indonesia, kemudian membawa bangsa Indonesia menuju kemerdekaan; dan pengetahuan tentang upaya-upaya kekuatan-kekuatan dari luar Indonesia untuk menguasai Indonesia dengan usaha-usaha dominasi ekonomi dan militer (Djono, 2011). Kedua aspek itu dapat dilihat melalui perjuangan Hassan Basry selama periode revolusi fisik (1945-1949).

Sebagai komandan ALRI Divisi IV Pertahanan Kalimantan (Ideham, dkk. 2004) tentu memiliki peran strategis terhadap keseluruhan proses perjuangan bangsa di Kalimantan Selatan yang puncaknya ketika ia membacakan sebuah "proklamasi" yang kemudian dikenal dengan "Proklamasi 17 Mei". Proklamasi 17 Mei pada hakekatnya merupakan pernyataan masyarakat Banjar yang diwakili oleh para elite pejuang, bahwa Kalimantan Selatan adalah bagian dari Republik Indonesia. Proklamasi ini juga menandai bahwa Kalimantan Selatan dan Kalimantan secara keseluruhan tidak pernah membentuk sebuah negara sebagaimana yang diinginkan oleh Van Mook, yakni membentuk negara federal. Sebuah penegasan jika orang Banjar sangat nasionalis.

Beberapa kendala dalam pengajaran sejarah untuk menanamkan sikap nasionalisme yakni (1) profesionalime guru sejarah, (2) terbatasnya alokasi waktu pelajaran sejarah, (3) sarana dan prasarana pembelajaran, (4) sikap siswa dalam proses pembelajaran, dan (5) perkembangan alat komunikasi. (Lamato dan Sudrajat, 2016). Berdasarkan latar belakang di atas maka tujuan penelitian ini adalah untuk mendeskripsikan nilai-nilai nasionalisme dalam perjuangan Hassan Basry untuk dijadikan sebagai sumber belajar sejarah di sekolah.

\section{METODE}

Penelitian ini menggunakan pendekatan deskriptif kualitatif karena bertujuan untuk menggali nilai-nilai kejuangan dari seorang tokoh pejuang. Data dikumpulkan dari berbagai sumber tertulis baik primer maupun sekunder untuk kemudian digali nilai-nilai nasionalisme Hassan Basry sebagai tokoh utama dalam perang mempertahankan kemerdekaan melalui jalur gerilya maupun diplomasi di Kalimantan Selatan. Data dianalisis dengan menggunakan model Miles dan Huberman (1992) yang dimulai dari reduksi data, display data dan verifikasi atau simpulan. Teknik keabsahan data dilakukan dengan triangulasi dengan menggali berbagai cara untuk menggali sumber untuk menemukan nilai-nilai nasionalisme Hassan Basry.

\section{TINJAUAN PUSTAKA}

\section{Pembelajaran Sejarah (Lokal)}

Menurut Kochhar (2008:16) pembelajaran sejarah merupakan pembelajaran yang mempelajari perilaku HISTORIA: Jurnal Pendidik dan Peneliti Sejarah, p-issn:2620-4789 | e-issn:2615-7993 manusia secara keseluruhan di masa lalu. Sedangkan I Gde Widja (1989: 23) menjelaskan bahwa pembelajaran sejarah adalah perpaduan antara aktivitas belajar mengajar yang di dalamnya mempelajari tentang peristiwa masa lampau. Kedua pengertian tersebut dapat dimaknai bahwa pembelajaran sejarah adalah proses belajar dalam bentuk aktivitas peserta didik yang terkait dengan masa lalu manusia.

Masa lalu manusia sangat kompleks, yakni aspek budaya, ekonomi, politik, sosial dan agama. Untuk mengetahui dan kemudian memahami aktivitas manusia pada masa lalu manusia yang kompleks oleh peserta didik, maka pembelajaran sejarah menjadi jembatan untuk membentuk kesadaran sejarah di sekolah. Melalui pembelajaran sejarah maka peserta didik mengalami proses internalisasi nilai, diantaranya nilai nasionalisme yang dapat digali dari berbagai sumber belajar yang terdapat di daerah (lokal) seperti nilai nasionalisme yang digali dari seorang tokoh pejuang Kalimantan Selatan pada periode revolusi fisik (1945-1949), yakni Hassan Basry. Pembelajaran sejarah lokal dapat membawa siswa dalam situasi ril yang ada di lingkungannya. Dalam konteks ini disebut kontekstual, yakni menggali sumber belajar yang ada di lingkungan siswa yang terdekat sehingga terasa lebih bermakna. Sikap inovatif dan profesionalisme guru sejarah memegang peranan dalam usaha mencari terobosan bagi kemungkinan pengembangan pengajaran sejarah lokal (Widja, 1989).

\section{Sumber Belajar (Sejarah)}

Kochhar (2008:160) menjelaskan bahwa sumber belajar adalah sarana pembelajaran dan pengajaran yang sangat penting untuk memperluas konsep, dan membangkitkan minat peserta didik. Diantara sumber belajar itu, yakni buku cetak, bahan bacaan tambahan, buku latihan, sumber-sumber bacaan terprogram, sumber-sumber referensi umum seperti ensiklopedi, surat kabar, atlas, pamflet, dan buku-buku terbitan pemerintah; buku-buku tambahan untuk bidang studi yang sedang dipelajari. Sedangkan menurut Majid (2009), sumber belajar adalah segala tempat atau lingkungan sekitar, benda, dan orang yang mengandung informasi yang dapat digunakan sebagai wahana bagi peserta didik untuk melakukan proses perubahan tingkah laku.

Sumber belajar merupakan sesuatu yang dimanfaatkan dan memberi kemudahan bagi siswa untuk memeroleh informasi, pengetahuan dan keterampilan dalam proses belajar mengajar sesuai dengan tujuan yang ingin dicapai (Sanjaya, 2009; Mulyasa, 2006). Tati (2006) menjelaskan bahwa diantara bahan ajar (sumber belajar) yang efektif bagi peserta didik yakni melalui penggalian sejarah dan budaya lokal, seperti adat istiadat, kesenian tradisi, situs, cerita rakyat, pahlawan, bahasa, peristiwa sebelum dan sesudah masuknya Islam, masa kolonial, masa kemerdekaan dan kontemporer.

Sumber belajar menurut bentuk dan isinya dapat dibedakan menjadi lima macam, yakni: (1) tempat atau lingkungan alam, artinya dimana saja seseorang bisa melakukan proses belajar atau perubahan tingkah laku, maka tempat tersebut dapat dikelompokan sebagai tempat belajar, contohnya perpustakaan, laboratorium, dan museum; (2) 
benda, adalah segala benda yang memungkinkan terjadinya perubahan tingkah laku bagi peserta didik, seperti situs, candi, dan benda-benda peninggalan lainnya; (3) orang, artinya siapa saja yang memiliki keahlian dan kemampuan tertentu dimana peserta didik dapat belajar sesuatu, contohnya guru, ahli geologis, politisi dan sebagainya; (4) buku, segala macam buku yang dapat dibaca secara mandiri oleh peserta didik, contohnya buku pelajaran, buku teks, kamus, ensiklopedia, dan lain sebagainya; (5) peristiwa dan fakta yang sedang terjadi contohnya adalah peristiwa kerusuhan, peristiwa bencana, dan peristiwa lainnya (Prastowo, 2012).

Perjuangan Hassan Basry sebagai sumber sejarah dalam pembelajaran sejarah yang dimaksud dalam penelitian ini adalah bahwa bagaimana guru sejarah memanfaatkan sebuah peristiwa dan fakta sejarah lokal yang memiliki fungsi strategis terhadap internalisasi nilai, yakni nilai-nilai nasionalisme melalui penggalian materi peristiwa dan fakta revolusi fisik (1945-1949) di Kalimantan Selatan yang dipimpin oleh Hassan Basry. Herbani (2016) menjelaskan bahwa untuk dapat meningkatkan rasa bangga dan Cinta Tanah Air (pariotisme) peserta didik maka dapat dilakukan melalui pengenalan tokoh sejarah lokal. Menurutnya, pengenalan tokoh Pangeran Diponegoro melalui museum Sasana Wiratama mampu meningkatkan karakter Cinta Tanah Air bagi peserta didik.

\section{PEMBAHASAN}

\section{Hassan Basry pada Awal Kemerdekaan: Memimpin Organisasi Kelaskaran}

Pascaproklamasi kemerdekaan pada 1945, Hassan Basry aktif dalam organisasi pemuda Kalimantan yang berpusat di Surabaya, yakni PRIK (Pemuda Republik Indonesia Kalimantan). Ia juga pemimpin Laskar Syaifullah di Kandangan (1946) tepatnya di Haruyan. Tahun 1946 ia memimpin Benteng Indonesia. Dari sini ia mengawali perjuangannya. Perjuangan rakyat menantang penjajahan di Kalimantan ternyata tidak pernah luput dari perhatian Hassan Basry, sekalipun ia tinggal di pulau Jawa (Wajidi, 2015).

Ketika di Jawa, ia mengabdi menjadi guru agama pada SMP Islam di Malang dan juga aktif dalam kegiatan organisasi. Sebagaimana dikemukakan putra keduanya, Ridha Tahya Basry (Wawancara, 17 Maret 2018), "sabalum abahku balum bajuang sidin manjadi guru di Gontor Ponorogo Jawa Timur, waktu itu sidin mengajar seabgai guru agama" (sebelum ayahku berjuang, dia menjadi guru di Gontor Ponorogo Jawa Timur, waktu itu dia sebagai guru agama).

Ketika Hassan Basry mendengar perlawanan rakyat Kalimantan dengan perjuangan yang makin memanas, ia terpanggil untuk pulang ke kampung halaman dengan tekad yang kuat ia berangkat dari Surabaya ke Kalimantan dengan menumpang kapal "Bintang Tulen". Perjalanan dilalui selama satu hari dan tiba di Banjarmasin pada 30 Oktober 1945. Orang pertama yang dihubungi adalah H. Abdurrahman Sidik, seorang ulama yang cukup terkenal pada waktu itu. Ia juga menghubungi berbagai organisasi perjuangan rakyat yang telah berdiri. Ketika itu sudah ada organisasi perlawanan rakyat yang diberi nama Laskar Syaifullah yang kemudian
Hassan Basry dipilih sebagai pemimpinnya (Wawancara, Nanang Ahmad, 13 Maret 2018).

Pada 5 Mei 1946, Laskar Syaifullah didirikan di Haruyan. Tokoh-tokohnya antara lain Asunawaty, Mansyah, Nawir, Baseri, Aini, Gazali, Hasyim, Hamzah dan Arifin. Kegiatan utama organisasi ini adalah latihan keprajuritan. Hassan Basry ditunjuk sebagai pemimpin. Pada 24 September 1946, Laskar Syaifullah melaksanakan kegiatan "pasar malam amal" yang bertujuan mencari dana pendidikan Islam. Kegiatan itu dicurigai Belanda. Beberapa tokoh-tokoh Laskar Syaifullah akhirnya ditangkap dan dipenjara, seperti Asunawaty, Gazali dan Hasyim (Wawancara, Nanang Ahmad, 13 Maret 2018). Hassan Basry dan beberapa orang lainnya dapat meloloskan diri dan menyingkir ke Gunung Ambilik, sekitar $20 \mathrm{KM}$ dari Haruyan. Dengan ditangkapnya beberapa tokoh itu maka organisasi itu bubar, kemudian Hassan Basry mangubah taktik perjuangannya dengan mendirikan organisasi baru dengan nama "Banteng Indonesia". Sebagian besar anggotanya berasal dari Laskar Syaifullah. Organisasi tersebut barsifat keprajuritan dan secara diam-diam memperkuat diri dengan latihan kemiliteran bertempat di Haruyan dan Tabuti. Banteng Indonesia berkembang pesat namun tetap secara rahasia dan bermarkas di pedalaman. Berita tentang perjuangan gerilya Kalimantan terdengar sampai ke pulau Jawa (Wajidi, 2015: 15).

Secara formal daerah Kalimantan Selatan saat itu dikuasai oleh pemerintah NICA (Nederlands Indies Civil Administration) di bawah penguasa Belanda Mayor A.L.Van Assenderp. Kehadirannya juga diboncengi tentera Australia atas nama tentara Sekutu di bawah komando Kolonel Robson. Perjuangan Hassan Basry dan Kawan-kawan dalam mempertahankan Kalimantan kemudian mendapat respons oleh ALRI divisi IV yang berpusat di Jawa Timur (Basry, 2003). Angkatan Laut Republik Indonesia (ALRI) Divisi IV berdiri di Mojokerto (Jawa Timur) tugasnya adalah mempersatukan kekuatan tenaga pejuang asal Kalimantan yang berada di pulau Jawa. Secara resmi kesatuan ini didirikan pada 4 April 1946 oleh Laksaman Muda M. Natsir dan Mojokerto ditetapkan sebagai markasnya (Wajidi, 2015).

Pada 15 November 1946 Letnan Asli Zuhri dan Letnan M. Mursid selaku anggota markas ALRI Divisi IV yang berada di Mojokerto diutus ke Kalimantan Selatan membantu Hassan Basry. Dalam pertemuannya, Letnan Asli Zuhri menyampaikan tugas yang diberikan oleh komandan ALRI Divisi IV kepada Hassan Basry, yakni untuk menyiapakan satu Batalyon ALRI Divisi IV di Kalimantan Selatan. Pembentukan Batalyon ini dilakukan Hassan Basry dengan cara melebur organisasi Banteng Indonesia yang dipimpinnya saat itu (Basry, 2003: 114).

Peleburan Banteng Indonesia diikuti pula dengan peleburan Pasukan Pembantu Tentara Republik Indonesia dan Tentara Kebangsaan Indonesia yang ada di Kalimantan Selatan. Dengan cara itu, ALRI Divisi IV menjadi mantap dan kuat. Hassan Basry diangkat sebagai komandan ALRI Divisi IV Kalimantan Selatan dengan kedudukan markasnya di Kandangan. Brigjend Hassan Basry senantiasa berkonsultasi dan mengadakan kontak dengan pimpinan gerakan 


\section{Syaharuddin, Heru Puji Winarso, Al Hidayatullah \\ Nilai-Nilai Nasionalisme Perjuangan Hassan Basry sebagai Sumber Belajar Sejarah}

perlawanan yang berada di sektor-sektor tertentu guna pemantapan. Kemudian setelah terjadinya perlawanan di Amuntai, yaitu pada bulan Januari 1948 diadakan pertemuan rahasia di Cukan Lipai. Dalam pertemuan itu hadir antara lain H. Aberani Sulaiman, M. Hammy AM, M. Japeri, AR. Haka, Daeng Gadul, Budhigawin (Basry, 2003).

Kegiatan perjuangan di daerah ini semakin ditingkatkan dengan melibatkan seluruh kekuatan fisik yang ada. Tekadnya adalah untuk menggempur pos militer dan menyerang pasukan Belanda. Untuk mewujudkan tujuan itu, maka diperlukan sarana berupa persenjataan. Adanya keterampilan rakyat dalam membuat senjata api, seperti pistol, senapan dum-dum, dan granat tangan serta meriam jarak dekat cukup membantu dalam perjuangan. Setelah persiapan matang, maka meletuslah pertempuran di Hambawang Pulasan. Strategi yang dilakukan adalah mencegat iring-iringan truk militer Belanda. Terjadilah pertempuran diantara kedua belah pihak. Pasukan Hassan Basry berhasil menggempur serta menewaskan sebagian besar pasukan Belanda. Mobil milik militer Belanda jatuh ke jurang. Sementara di pihak ALRI Divisi IV gugur dua orang pejuang.

Di kota Barabai, Alabio, Birayang, Kandangan, dan lainlain beredar pamflet-pamflet yang isinya ditujukan untuk penduduk yang berstatus pegawai dan bekerja pada kantor pemerintahan Belanda. Isi pamflet adalah anjuran agar mereka ikut melakukan pemberontakan kepada penguasa. Belanda tidak diam, mereka pun menyebar isu tentang adanya anak buah Hassan Basry bernama Sapar Ancau seorang ektrimis kepala kampung di Paringin. Isu itu menyebar hingga ke seluruh Kalimantan Selatan. Isu itu cukup efektif karena para kepala kampung kemudian merasa terancam (Wawancara, Sakaruddin, 13 Maret 2018).

Sebagai pimpinan ALRI Divisi IV Hassan Basry mengatur strategi gerilyanya dengan berpindah-pindah, menyerang atau mencegat, kemudian menghindarkan diri. Kondisi ini mengharuskan Markas ALRI Divisi IV berpindah-pindah, diantaranya ke Pagat, Haliau, dan Hantakan. Ketiga tempat itu merupakan desa-desa yang berada di luar kota Barabai dan daerah tersebut dikenal sebagai pusat kekuatan militer Belanda. A. G. Deelman selaku residen benar-benar khawatir. Berdasarkan laporan kyai besar Hulu Sungai di Kandangan menyatakan tidak sanggup lagi menguasai situasi kacau akibat serangan orang-orang Republik (Wawancara, Rahmani, 13 Maret 2018).

Perkembangan politik di tingkat pemerintah pusat menyebabkan posisi Hassan Basry dan pasukannya mengalami kesulitan. Sesuai dengan perjanjian Linggarjati tanggal 25 Maret 1947, Belanda hanya mengakui kekuasaan De Facto RI atas Jawa, Madura dan Sumatera. Yang berarti Kalimantan merupakan wilayah yang berada di bawah kekuasaan Belanda. Akan tetapi, Brigjend Hassan Basry tidak terpengaruh oleh perjanjian tersebut, ia dan pasukannya tetap melanjutkan perjuangannya melawan Belanda (NICA). Sikap yang sama juga diperlihatkan pula terhadap perjanjian Renville (17 Januari 1948), Hassan Basry menolak memindahkan pasukannya ke daerah yang masih dikuasai RI, yaitu Jawa (Barjie, 2013).

\section{Proklamasi 17 Mei: Wujud Nilai Nasionalisme Orang Banjar}

Perjuangan "bawah tanah" Hassan Basry di Kalimantan Selatan selalu merepotkan pertahanan Belanda pada masa itu. Puncaknya, ketika Hassan Basry berhasil memproklamasikan kedudukan Kalimantan Selatan sebagai bagian dari Republik Indonesia yang dikenal dengan "Proklamasi 17 Mei 1949" (Wawancara, Wajidi, 17 Maret 2018). Bunyi Proklamasi tersebut ialah sebagai berikut:

Merdeka!

Dengan ini kami rakyat Indonesia di Kalimantan Selatan mempermaklumkan berdirinya pemerintahan Gubernur Tentara ALRI melingkupi seluruh daerah Kalimantan Selatan menjadi bagian dari Republik Indonesia untuk memenuhi isi Proklamasi 17 Agustus 1945 yang ditandatangani oleh Presiden Soekarno dan Wakil Presiden Mohammad Hatta.

Hal-hal yang bersangkutan dengan pemindahan kekuasaan akan dipertahankan dan kalau perlu diperjuangkan sampai tetesan darah yang penghabisan.

Tetap merdeka.

Kandangan, 17 Mei IV REP.

Atas nama rakyat Indonesia

Di Kalimantan Selatan

Gubernur Tentara,

Hassan Basry (Basry, 2003: 66-67).

"Proklamasi 17 Mei" mengandung beberapa nilai kejuangan, Pertama, Proklamasi merupakan sebuah pernyataan "sikap setia" kepada NKRI. Sikap setia dalam hal ini adalah sikap masyarakat Banjar untuk tetap mempertahankan diri dari menerima gagasan Van Mook untuk tidak menerima konsep negara federal. (Asnawi, dkk. 1994). Kedua, Proklamasi 17 Mei merupakan pernyataan kebulatan hati rakyat Banjar untuk merealisasikan kekuasaan Republik Indonesia di Kalimantan Selatan berlandaskan Proklamasi 17 Agustus 1945; Ketiga, Proklamasi 17 Mei memperlihatkan sebuah eksistensi, kekuatan, dan kemampuan rakyat Kalimantan Selatan untuk menyusun pemerintahan dalam lingkungan RI. Para pejuang dan Hassan Basry kemudian mendeklarasikan Pemerintahan Gubernur tentara ALRI yang berposisi di Kalimantan Selatan beserta unsur-unsur birokratnya; Keempat, "Proklamasi 17 Mei" merupakan sikap penolakan, pembangkangan masyarakat Banjar atas sikap arogansi, nafsu berkuasa kembali oleh Pemerintah Belanda dan ide negara federal oleh Gubernur Jenderal Van Mook.

Penolakan dimulai dengan membentuk partai (SKI dan SERMI) sebagai wadah menuangkan aspirasi politik secara formal; Kelima, Peristiwa "Proklamasi 17 Mei" merupakan sebuah keputusan yang tepat bagi Hassan Basry dan menegaskan kepada 'dunia' bahwa Pemerintah RI yang berpusat di Jawa, Pemerintah Belanda dan juga dunia internasional-- bahwa masyarakat Banjar di Kalimantan bagian Selatan (Residensi Borneo Selatan) masih eksis dan 'berdaulat.' Tentu ini merupakan sikap kepemimpinan yang membanggakan dari seorang Hassan Basry dan juga kelompok 
masyarakat Banjar lainnya di wilayah Kalimantan. Namun hal yang terpenting dari semua itu, adalah adanya usaha yang berani, percaya diri dan tidak kenal menyerah untuk tetap mempertahankan Proklamasi kemerdekaan di Kalimantan Selatan yang sangat dipengaruhi dengan nilai budaya Banjar yang dikenalkan oleh Pangeran Antasari, pimpinan Perang Banjar (1859-1906), yaitu dengan semboyan, haram manyarah, waja sampai kaputing (Ideham, dkk. 2004).

\section{Kiprah Hasan Basry Pascaperang: Belajar ke Cairo hingga Presiden ULM}

Selesai perang kemerdekaan, Hassan Basry melanjutkan pendidikan ke Universitas Al Azhar (1951-1953). Tidak begitu jelas mengapa ia "diasingkan” ke Mesir. Kemungkinan karena situasi politik waktu itu sehingga ia harus ke Mesir yang cukup berpengaruh terhadap karier politiknya di militer kemudian hari. Kemudian ia melanjutkan pendidikan di American University Cairo (1953-1955) dan sekolah Staff Komando Angkatan Darat di Bandung (1956), pada tahun itu juga Hassan Basry dilantik sebagai komandan Resimen Infanteri 21/Komandan Territorial VI KALSEL, dan pada tahun 1959, ia ditunjuk sebagai panglima daerah militer X Lambung Mangkurat dengan pangkat Kolonel, jabatan ini di embannya sampai tahun 1961 (Basry, 2003).

Pada saat itu suasana politik kian memanas karena sepak terjang PKI dan ormasnya. Hassan Basry mengeluarkan surat pembekuan kegiatan PKI beserta ormasnya pada tanggal 22 Agustus 1960 di seluruh wilayah Kalimantan Selatan. Dengan keluarnya surat itu, ia "ditegur" oleh Presiden Soekarno, namun ia sebagai kepala penguasa perang daerah Kalimantan Selatan tidak takut dan tidak peduli dengan teguran presiden itu. Ia sangat yakin bahwa keputusannya membekukan kegiatan PKI adalah final dan strategis untuk menyelamatkan Pancasila dan bangsa. Hal ini terbukti kemudian, pada September 1965 terjadi kudeta berdarah yang diduga kuat merupakan gerakan komunis (PKI) (Manihuruk, 1984). Pembekuan PKI dan ormasnya di Kalimantan Selatan diikuti pula oleh Sulawesi Selatan dan Sumatera Selatan dan peristiwa ini dikenal dengan "tiga Selatan" (Wawancara, Wajidi, 10 Maret 2018).

Pada tahun 1961-1963 Hassan Basry menjabat sebagai deputi wilayah komando antar Kalimantan dengan pangkat Brigadir Jenderal, pada tanggal 17 Mei 1961, bertepatan dengan peringatan Proklamasi Kalimantan Selatan, sebanyak 11 organisasi politik dan militer menetapkan Brigjend Haji Hassan Basry sebagai bapak Gerilya Kalimantan. Kesepakatan ini diikuti oleh penetapan DPR-GR tingkat II Hulu Sungai Utara pada tanggal 20 Mei 1962, yakni ketetapan Brigjend Haji Hassan Basry sebagai bapak Gerilya Kalimantan (Basry, 2003: 95).

Pada tahun 1960-1966, Brigjend Haji Hassan Basry menjadi anggota MPRS. Selanjutnya pada tahun 1970, ia diangkat sebagai Ketua Umum Dewan Harian Angkatan 45 Kalimantan Selatan sekaligus sebagai Dewan Paripurna angkatan 45 pusat dan Dewan Paripurna Pusat Legiun Veteran Republik Indonesia. Pada tahun 1978-1982, Hassan Basry menjadi anggota DPR. Sebagai tokoh berlatar belakang pejuang Kalimantan, ia dipercaya manjadi Pangdam X
Lambung Mangkurat yang pertama di Kalimantan Selatan (Basry, 2003).

Pada masa Hassan Basry aktif bertugas di Kalimantan Selatan ia berperan besar dalam proses pendirian Universitas Lambung Mangkurat Banjarmasin (ULM), yang merupakan Universitas Negeri tertua dan terbesar di Kalimantan Selatan. Bermula pada acara reuni tahun 1957, para pejuang membentuk Dewan Lambung Mangkurat yang bertujuan membangun Kalimantan Selatan. Setahun kemudian, maka dibentuklah Panitia Persiapan Pembentukan Universitas Lambung Mangkurat. Beberapa tokoh nasional asal Kalimantan Selatan ikut terlibat, seperti KH. Idham Chalid (Wakil Perdana Menteri), Ir. PM. Noor (Menteri Pekerjaan Umum dan Tenaga) dan Tjilik Riwut (Gubernur Kalimantan Tengah). Maka pada tanggal 21 September 1958 berhasil mendirikan ULM dengan Letkol Hassan basry sebagai presiden (Rektor). Dan, pada 1 November 1960 diresmikan oleh Presiden RI berdasarkan PP No. 41 Tahun 1960 yang terdiri dari empat fakultas, yakni: Fakultas Hukum, Ekonomi, Sosial Politik, dan Pertanian.

Brigjend Hassan Basry meninggal dunia pada tanggal 15 Juli 1984 setelah sakit dan dirawat di RSPAD Gatot Subroto Jakarta. Pemakaman Brigjend Haji Hassan Basry dilaksanakan secara militer dengan inspektur upacara Mayjen AE. Manihuruk, ia dimakamkan di Simpang Liang Anggang Banjarbaru Kalimantan Selatan. Atas jasa-jasanya, Brigjend Haji Hassan Basry dianugerahi gelar "Pahlawan Kemerdekaan" oleh Presiden Republik Indonesia (Barjie, 2013: 212).

Menurut Ridha Tahya Basry (Wawancara, 17 Maret 2018) bahwa Hasan Basry berpesan agar jika nanti meninggal agar dimakamkan di pemakaman umum. Berdasarkan kesepakatan keluarga dan para tokoh masyarakat, maka ia dimakamkan di Liang Anggang yang saat ini sekaligus dijadikan sebagai monument ALRI Divisi IV Kalimantan. Dalam konteks ini Hassan Basry memberikan teladan bahwa pangkat, kedudukan dan jabatan bukan hal yang harus ditampakkan, tapi perjuangan, kesungguhan dan keikhlasan dalam membela bangsa jauh lebih penting. Hal inilah mengapa kemudian ia tidak ingin dimakamkan di Taman Makam Pahlawan.

\section{SIMPULAN}

Perjuangan Hassan Basry dimulai sejak ia memimpin Laskar Saifullah bersama-sama dengan pejuang lainnya pada awal kemerdekaan. Sebelumnya, ia juga aktif mengikuti organisasi perjuangan di Surabaya, diantaranya, yakni Barisan Pemberontak Republik Indonesia Kalimantan (BPRIK) dan Pemuda Republik Indonesia Kalimantan (PRIK).

Ketika Sekutu yang diboncengi NICA menduduki Kalimantan, maka Hassan Basry dan para pejuang lainnya ikut membentuk berbagai laskar dan badan-badan perjuangan di Kalimantan Selatan bersama dengan ALRI DIVISI IV yang berpusat di Tuban. Puncaknya, ketika Hassan Basry mengikrarkan "Proklamasi 17 Mei" di Kandangan yang intinya bahwa Kalimantan menolak pembentukan Negara Kalimantan oleh Van Mook, dan sebaliknya Kalimantan Selatan tetap "setia" terhadap NKRI yang berpusat di Yogyakarta. "Proklamasi 17 Mei" mengandung nilai-nilai nasionalisme, yakni nilai kesetiaan; nilai keberanian; dan nilai 


\section{Syaharuddin, Heru Puji Winarso, Al Hidayatullah \\ Nilai-Nilai Nasionalisme Perjuangan Hassan Basry sebagai Sumber Belajar Sejarah}

pantang menyerah yang telah ditunjukkan kepada pemerintah Hindia Belanda dan dunia bahwa masyarakat Indonesia di Kalimantan Selatan masih "ada" dan berjuang sampai tetes darah yang penghabisan yang dalam istilah lokal "haram manyarah, waja sampai kaputing" merupakan slogan yang telah dipopulerkan oleh Pangeran Antasari sejak periode Perang Banjar (1859-1906) .

Pengembangan sumber belajar sejarah tidak cukup hanya berdasarkan buku teks yang telah ada, namun dapat mengoptimalkan nilai-nilai sosial budaya yang ada di lingkungan peserta didik, seperti nilai-nilai kejuangan (nasionalisme) Hassan Basry yang mengandung nilai kesetiaan; nilai keberanian; dan nilai pantang menyerah yang memiliki fungsi strategis terhadap pengembangan sumber belajar sejarah dan berimplikasi terhadap pembentukan karakter bangsa (nation and character building) yang penting dalam mengisi pembangunan bangsa dan dalam menghadapi era persaingan global.

\section{REFERENSI}

Anwar, Chairul. (2014). "Internalisasi Semangat Nasionalisme Melalui Pendekatan Habituasi (Perspektif Filsafat Pendidikan)". Jurnal Analisis (Jurnal Studi Keislaman), Volume 14, Nomor 1, Juni 2014. Tersedia: https://media. neliti.com/media/publications/57533-ID-internalisasisemangat-nasionalisme-mela.pdf. Diakses tanggal 2 februari 2019.

Asnawi, A.dkk. (1994). Sejarah Perjuangan Rakyat Menegakkan Kemedekaan Republik Republik Indonesia di Kalimantan Selatan (1945-1949). Banjarmasin: Pemerintah Daerah Provinsi Kalimantan Selatan.

Barjie, Ahmad B. (2013). Tokoh Banjar Dalam Sejarah (Antara Legenda dan Kisah Nyata). Banjarmasin: CV. Rahmat Hafiz Al Mubaraq.

Basry,Hassan.(2003). Kisah Geriya Kalimantan Jilid I dan Jilid II. Banjarmasin: Yayasan Bhakti Banua.

Djono. (2011). "Pengembangan Bahan Ajar Sejarah Berbasis Muatan Lokal". Dalam Agus Mulyana dan Wawan Darmawan (editor). (2011). "Pendidikan Sejarah dalam Membangun Masa Depan Bangsa". Prosiding Seminar Nasional Pendidikan Sejarah, UPI Bandung.

Herbani, A. (2016). "Peran Museum Sasana Wiratama Dalam Meningkatkan Rasa Cinta Tanah Air Masyarakat Desa Tegalrejo, Kecamatan Tegalrejo, Yogyakarta”. Jurnal Istoria: Jurnal Pendidikan dan Ilmu Sejarah, Volume 11 No 2 Maret 2016, hal. 71-78. Tersedia: https://journal. uny.ac.id/index.php/istoria/article/view/9556. Diakses tanggal 9 Februai 2019.

Ideham, I, dkk. (2004). Sejarah Banjar. Banjarmasin: Pemerintah Provinsi Kalimantan Selatan.

Kahin, George Mc Turnan. (1995). Nasionalisme dan Revolusi Indonesia. Solo: Sebelas Maret University Press bekerjasama dengan Pustaka Sinar Harapan.

Kochar, S. K. (2008). Pembelajaran Sejarah: Teaching of History. Jakarta: Grasindo.

Kemendikbud. (2010). Bahan Pelatihan: Penguatan Metodologi Pembelajaran Berdasarkan Nilai-Nilai Budaya untuk
Membentuk Daya Saing dan Karakter Bangsa. Jakarta: Kemendikbud Balai Penelitian dan Pengembangan Pusat Kurikulum.

Lamato, Sinyo A. dan Sudrajat, Ajat. (2016). "Penanaman Kesadaran Sejarah Dan Sikap Nasionalisme Dalam Pembelajaran Sejarah Di Sma Negeri 2 Banggai”. Jurnal Istoria: Jurnal Pendidikan dan Ilmu Sejarah, Volume 12 No 1 September 2016, hal. 71-78. Tersedia: https:// journal.uny.ac.id/index.php/istoria/article/view/9556. Diakses tanggal 9 Februai 2019.

Manihuruk, A.E. (1984). Mengenang Alm, Brigjend (TNI) Purn. Hassan Basry, Bapak Gerilya Kalimantan. Banjarmasin: DPD AMPI.

Miles, M.B dan Huberman, A.M. (1992). Analisis Data Kualitatif. Jakarta: UI Press.

Mulyasa, E. (2006). Menjadi Guru Profesional. Bandung: PT Remaja Rosdakarya.

Prastowo, Andi. (2012). Panduan Kreatif Membuat Bahan Ajar Inovatif. Yogyakarta: Diva Press.

Sanjaya, W. (2009). Strategi Pembelajaran Berorientasi Standar Proses Pendidikan. Jakarta: Kencana Prenada Media Group.

Smith, Anthony D. (2003). Nasionalisme: Teori, Ideologi, Sejarah. Jakarta: Erlangga.

Syaharuddin. (2017). Orang Banjar Menjadi Indonesia: Dinamika Organisasi Islam di Borneo Selatan, 1912-1942. Yogyakarta: Eja Publisher.

Tati, Andi Dewi Riang. (2006). "Analisis Kebutuhan Bahan Ajar Muatan Lokal Sejarah dan Budaya Kabupaten Bone di Sekolah Dasar". Jurnal Istoria: Jurnal Pendidikan dan Ilmu Sejarah, Volume 12 No 1 September 2016, hal. 7386. Tersedia: https://journal.uny.ac.id/index.php/istoria/ article/view/9556. Diakses tanggal 9 Februai 2019.

Wajidi. 2015. Revolusi Kemerdekaan di Kalimantan Selatan 1945-1949. Penerbit Ombak; Yogyakarta.

Widja, I Gede. (1989). Sejarah Lokal Suatu Perspektif dalam Pengajaran Sejarah. Jakarta: Depdibud.

Wiriaatmadja, R. (2002). Pendidikan Sejarah di Indonesia: Perspektif Lokal, Nasional dan Global. Bandung: Rizqi Offset.

Wawancara:

Rahmani. (80 tahun). Pekerjaan: Veteran Pejuang Revolusi Fisik (1945-1949). Alamat: Banjarmasin. Tanggal Wawancara: 13 Maret 2018.

Ridha Tahya Basry. (59 tahun). Pekerjaan: Pensiunan Bank. Putera kedua Brigjend Hassan Basry. Alamat: Banjarmasin. Tanggal Wawancara: 17 Maret 2018.

Sakaruddin. (84 tahun). Pekerjaan: Veteran Pejuang Revolusi Fisik. Alamat: Banjarmasin. Tanggal Wawancara: 12 Maret 2018.

Wajidi. (48 tahun). Pekerjaan: PNS Pada Badan Penelitian dan Pengembangan Provinsi Kalimantan Selatan. Alamat: Banjarmasin. Tanggal Wawancara 10 Maret 2018.

HISTORIA: Jurnal Pendidik dan Peneliti Sejarah, p-issn:2620-4789 | e-issn:2615-7993 